\title{
A comparison of responses to bronchodilator drugs in chronic bronchitis and chronic asthma
}

\author{
GRAHA M K C R O M P T N \\ From the Department of Respiratory Diseases, University of Edinburgh, City Hospital, Edinburgh
}

Isoprenaline by inhalation, adrenaline by inhalation, subcutaneous adrenaline, intravenous aminophylline, and subcutaneous atropine were administered to two groups of 18 patients suffering from either chronic bronchitis or chronic asthma using a Latin square design. Prednisolone was then given to both groups of patients for six days. The responses to the drugs were assessed by recording the F.E.V $\cdot_{1.0}$ before and 20 minutes after the administration of the short-acting drugs and daily during the period of prednisolone therapy. No significant differences were found between the responses to the short-acting antispasmodic drugs in the group of patients suffering from chronic bronchitis and only an insignificant improvement in the mean F.E.V. $\cdot{ }_{\cdot 1 \cdot 0}$ occurred during the period of prednisolone administration. Significant differences between mean responses to the anti-spasmodic drugs of the group of patients suffering from chronic asthma were observed. The mean F.E.V.$_{1 \cdot 0}$ response following subcutaneous adrenaline was $44 \%$, which was significantly better than the $23.7 \%$ improvement after adrenaline inhalation $(P=0.005)$ and the mean improvement in F.E.V..$_{1 \cdot 0}$ of $17 \cdot 1 \%$ after subcutaneous atropine sulphate $(P=0.001)$. A dramatic improvement in the mean F.E.V..$_{1 \cdot 0}$ of $49.5 \%$ occurred after six days of prednisolone administration. It is tentatively suggested that a good response to subcutaneous adrenaline and a poor response to subcutaneous atropine, as judged by improvement in the F.E.V $\cdot_{1 \cdot 0}$, may be an indication that a good response to prednisolone can be expected in wheezy patients.

The objective responses to bronchodilator drugs are commonly used in the assessment of patients with airways obstruction. Isoprenaline given by inhalation is considered by many physicians to be the most efficient short-acting bronchodilator drug and would therefore appear to be the drug of choice for assessing the degree of reversible airways obstruction. The response to isoprenaline and other bronchodilator drugs, however, varies according to the severity of 'bronchospasm' at the time of the test (Hume and Gandevia, 1957 ; Hume and Rhys Jones, 1961). Some clinicians prefer adrenaline to isoprenaline. It has been reported that the injection of adrenaline has little or no advantage over the inhalation route in asthmatic patients not in severe status asthmaticus (Kennedy, 1961).

Aminophylline is frequently used in the treatment of wheezy patients, but little information is available about its efficacy compared with other bronchodilator drugs.

Cholinergic drugs have long been known to have bronchodilator properties (Finnegan, 1950), and it has been suggested that there are different responses to atropine in asthma and in chronic bronchitis, the variation in response having some correlation with the response to corticosteroid drugs (Altounyan, 1964).

There is now no doubt about the benefit of corticosteroid drugs in the treatment of some asthmatic patients (Thursby-Pelham and Kennedy, 1958 ; Somner, Rogan, and Grant, 1960 ; Phear, Ball, and Page, 1960), but their place in the treatment of wheezy chronic bronchitis is less clear. It is sometimes difficult to differentiate clinically between patients with wheezy chronic bronchitis and patients suffering from chronic asthma, and because of this it is common practice to give a trial of corticosteroid drugs to most wheezy patients. By doing this a few patients thought to have chronic bronchitis are found to respond dramatically - as judged by the objective assessment of ventilatory function tests-and it is likely that this small group of patients have chronic asthma as their dominant disease and not chronic bronchitis. It may be argued that corticosteroid 
drugs can, in fact, be dangerous when given to patients suffering from chronic bronchitis, especially in relation to hospital infection. Also a patient's stay in hospital is usually lengthened when corticosteroid drug assessment is performed. It would therefore be of considerable value if some indication could be obtained of a wheezy patient's probable response to corticosteroid drugs from the results of tests using simple bronchodilator drugs.

With these points in mind, it was decided to assess the effects of some commonly used bronchodilator drugs and prednisolone in patients suffering from chronic bronchitis and chronic asthma.

\section{MATERIAL}

Two groups of wheezy patients were selected for study. Group 1 consisted of 18 patients suffering from chronic bronchitis. All had cough and sputum occurring on most days for more than three months in the year for at least two years, and all complained of distressing wheeze and breathlessness. These patients were selected from the many chronic bronchitic patients admitted to the Respiratory Disease Unit at Edinburgh over a period of two years. They were chosen because of their distressing wheeze and because I thought that such a group might show more objective response to bronchodilator drugs than an unselected group of patients with chronic bronchitis. There were 12 men and 6 women in this group. Their ages ranged from 36 to 71 years (men 45 to 71 years and women 36 to 67 years). Eleven patients were cigarette smokers at the time of the study. Four patients had been cigarette smokers but had stopped prior to the study. Three of the women had never smoked.

Group 2 consisted of 18 patients with chronic asthma who were not at the time of the study being treated with corticosteroid drugs. In the selection of this group of patients, certain features of their history were used to diagnose chronic asthma as opposed to chronic bronchitis. Particular attention was paid to the mode of development, nocturnal exaggeration of symptoms as opposed to wheeze on getting up in the morning, and the smoking habits.

There were 14 men and 4 women in this group. Their ages ranged from 32 to 68 years (men 34 to 68 years and women 32 to 44 years). One patient in this group was a cigarette smoker at the time of the study; nine had stopped smoking; seven gave no smoking history; and one was a pipe smoker.

Both groups were chosen on purely clinical grounds. The results of previous ventilatory function tests, if they had been performed, were not taken into consideration. Full details of the patients are given in Tables I and II, and pretreatment F.E.V. levels are recorded.

\section{METHODS}

The following drugs and methods of administration were used :

(1) Isoprenaline sulphate $2 \%$ inhalation

(2) Adrenaline $\mathrm{HCl} 1: 100$ inhalation

(3) Adrenaline $\mathrm{HCl}$ 1:1,000 subcutaneous injection $(0.5 \mathrm{ml}$.)

(4) Aminophylline intravenous injection $(0.5 \mathrm{~g}$.)

(5) Atropine sulphate subcutaneous injection (0.6 mg.)

(6) Saline inhalation.

The inhalations were given using a Wright nebulizer for three minutes with an oxygen flow rate of 8 litres per minute.

The order of drug administration was randomized by the use of Latin squares, the drug sequence for each patient not being known until the morning of the first test. All tests were performed by the author on consecutive mornings between the hours of 8 a.m. and $10 \mathrm{a} . \mathrm{m}$. in order to avoid diurnal variation in tests of respiratory function (Lewinsohn, Capel, and Smart, 1960). The one-second forced expiratory volume (F.E.V.1.0) was recorded using a modified Gaensler spirometer (McKerrow, McDermott, and Gilson, 1960). Three recordings of the F.E.V.1.0 were made before the drugs were given and again 20 minutes after drug administration. The best of the three F.E.V.1.0 recordings was accepted.

After the six tests had been completed, prednisolone, $40 \mathrm{mg}$. daily, was given and daily recordings of three F.E.V.1.0 measurements were made on six consecutive mornings.

Some of the patients were receiving bronchodilator drugs as part of their routine ward treatment, but these drugs were not administered until after the morning test had been performed. The patients who had their own 'inhalers' were instructed not to use them after 4 a.m. and only short-acting preparations containing isoprenaline alone were allowed to avoid any possible carry-over effect of inhalations containing isoprenaline and atropine methonitrate.

\section{RESULTS}

The responses to the six drugs used in the first part of the study were calculated as changes in F.E.V ${ }_{\cdot 1 \cdot 0}$ expressed as percentages of the pretreatment values. A single pretreatment value was chosen in preference to a mean of all the values in the previous week, because a number of the asthmatic patients showed some spontaneous improvement in their F.E.V. readings during the week before prednisolone was administered, and therefore a mean of all the values during the first week would have tended to exaggerate the prednisolone response. Also during prednisolone therapy the changes in F.E.V..$_{1 \cdot 0}$ over the period of six days were expressed as percentages of the preprednisolone treatment values. 
T A B L E I A

GROUP 1, CHRONIC BRONCHITIS

\begin{tabular}{|c|c|c|c|c|}
\hline $\begin{array}{l}\text { Patient } \\
\text { Sex/Age }\end{array}$ & $\begin{array}{l}\text { History of Cough } \\
\text { and Wheeze }\end{array}$ & $\begin{array}{l}\text { Other Points of } \\
\text { Significance }\end{array}$ & $\begin{array}{l}\text { Smoking } \\
\text { History }\end{array}$ & $\begin{array}{l}\text { Eosinophils in Blood } \\
\text { and Sputum }\end{array}$ \\
\hline$\underset{67}{\mathbf{F}}$ & $\begin{array}{l}\text { Daily cough } 30 \text { yrs. Sputum daily } 5 \text { yrs, rarely } \\
\text { purulent. Distressing wheeze } 3 \text { yrs. Cough and } \\
\text { wheeze worse in mornings and at night }\end{array}$ & Nil & Non-smoker & $\begin{array}{l}10 \% \text { eosinophils of } 8,100 \\
\text { total white cell count. No } \\
\text { eosinophils in sputum }\end{array}$ \\
\hline$\underset{58}{\mathbf{F}}$ & $\begin{array}{l}\text { Daily cough } 5+\text { yrs. Sputum daily } 5 \text { yrs, mainly } \\
\text { mucoid but purulent every winter. Wheeze } 5 \text { yrs. } \\
\text { No nocturnal exaggeration of symptoms }\end{array}$ & Nil & $\begin{array}{l}20 \text { cigarettes daily } \\
\text { for } 37 \text { yrs }\end{array}$ & $\begin{array}{l}\text { Normal differential white } \\
\text { cell count. No eosinophils } \\
\text { in sputum }\end{array}$ \\
\hline$\underset{63}{\text { J.D. }}$ & $\begin{array}{l}\text { Cough } 10+\text { yrs. Sputum during winter months } 10 \text { yrs, } \\
\text { frequently purulent. Cough and wheeze worse in } \\
\text { mornings. Symptoms less marked during summer } \\
\text { months }\end{array}$ & Nil & $\begin{array}{l}20+\text { cigarettes daily } \\
\text { for } 50 \text { yrs }\end{array}$ & $\begin{array}{l}\text { Normal differential white } \\
\text { cell count. No eosinophils } \\
\text { in sputum }\end{array}$ \\
\hline $\begin{array}{l}\text { W.R. } \\
47\end{array}$ & $\begin{array}{l}\text { Cough } 40 \text { yrs. Daily sputum } 10 \text { yrs, frequently puru- } \\
\text { lent. Daily wheeze } 5 \text { yrs, worse when sputum } \\
\text { purulent. No nocturnal exaggeration of symptoms }\end{array}$ & Nil & $\begin{array}{l}20+\text { cigarettes daily } \\
\text { for } 30 \mathrm{yrs}\end{array}$ & $\begin{array}{l}\text { Normal differential white } \\
\text { cell count. No eosinophils } \\
\text { in sputum }\end{array}$ \\
\hline$\underset{55}{\mathbf{F}}$ & $\begin{array}{l}\text { Intermittent cough } 20 \text { yrs. Daily cough } 5 \text { yrs. Daily } \\
\text { sputum } 3 \text { yrs, occasionally purulent. Progressive } \\
\text { daily wheeze } 2 \text { yrs. Cough and wheeze worse in } \\
\text { mornings }\end{array}$ & Nil & $\begin{array}{l}10 \text { - } 15 \text { cigarettes daiiy } \\
\text { for } 30 \text { yrs }\end{array}$ & $\begin{array}{l}\text { Normal differential white } \\
\text { cell count. No eosinophils } \\
\text { in sputum }\end{array}$ \\
\hline $\begin{array}{l}\text { J.L. } \\
\mathbf{M} 1\end{array}$ & $\begin{array}{l}\text { Cough } 25 \text { yrs. Daily cough } 10 \text { yrs. Daily sputum } 10 \\
\text { yrs, frequently purulent. Intermittent wheeze } 20 \text { yrs. } \\
\text { Daily distressing wheeze } 5 \text { yrs. Cough and wheeze } \\
\text { worse in mornings }\end{array}$ & Nil & $\begin{array}{l}30-50 \text { cigarettes daily } \\
\text { for } 35 \text { yrs }\end{array}$ & $\begin{array}{l}\text { Normal differential white } \\
\text { cell count. No eosinophils } \\
\text { in sputum }\end{array}$ \\
\hline$\underset{63}{\text { P.R. }}$ & $\begin{array}{l}\text { Daily cough worse in winter months } 10 \text { yrs. Sputum } \\
\text { purulent after colds usually in winter months. Daily } \\
\text { progressive wheeze } 6 \text { yrs. Cough and wheeze worse } \\
\text { in mornings }\end{array}$ & Nil & $\begin{array}{l}15 \text { cigarettes daily } \\
\text { for } 45 \text { yrs }\end{array}$ & $\begin{array}{l}\text { Normal differential white } \\
\text { cell count. No eosinophils } \\
\text { in sputum }\end{array}$ \\
\hline$\underset{65}{\text { R.G. }}$ & $\begin{array}{l}\text { Cough after head colds } 10 \text { yrs. Daily cough and } \\
\text { sputum } 5 \text { yrs. Sputum frequently purulent. Progres- } \\
\text { sive daily wheeze } 2 \text { yrs. Cough and wheeze worse in } \\
\text { mornings }\end{array}$ & Nil & $\begin{array}{l}20 \text { cigarettes daily } \\
\text { for } 40 \text { yrs }\end{array}$ & $\begin{array}{l}\text { Normal differential white } \\
\text { cell count. No eosinophils } \\
\text { in sputum }\end{array}$ \\
\hline$\underset{\mathbf{M}}{\mathbf{M}}$ & $\begin{array}{l}\text { Recurrent cough } 16 \text { yrs. Daily cough and sputum } 10 \\
\text { yrs. Sputum frequently purulent. Daily wheeze } \\
8 \text { yrs. Cough and wheeze worse in mornings }\end{array}$ & Nil & $\begin{array}{l}15 \text { cigarettes daily for } \\
50 \text { yrs. Stopped } 3 \\
\text { yrs before study } \\
\text { for financial reasons }\end{array}$ & $\begin{array}{l}\text { Normal differential white } \\
\text { cell count. No eosinophils } \\
\text { in sputum }\end{array}$ \\
\hline $\begin{array}{r}\text { E.P. } \\
\text { F }\end{array}$ & $\begin{array}{l}\text { Winter 'bronchitis' most of life. Daily cough } 6 \text { yrs. } \\
\text { Sputum daily } 5 \text { yrs, mainly mucoid. Daily wheeze } \\
5 \text { yrs. Cough and wheeze worse in mornings. Occa- } \\
\text { sional nocturnal wheeze. Symptoms less severe in } \\
\text { winter months }\end{array}$ & Nil & Non-smoker & $\begin{array}{l}\text { Normal differential white } \\
\text { cell count. No eosinophils } \\
\text { in sputum }\end{array}$ \\
\hline$\underset{\mathbf{M 7}}{\mathbf{M}}$ & $\begin{array}{l}\text { Cough after colds many years. Daily cough and } \\
\text { sputum } 6 \text { yrs. Sputum frequently purulent. Wheeze } \\
\text { daily } 3 \text { yrs. Intermittent mild wheeze when sputum } \\
\text { purulent } 6 \text { yrs. Cough and wheeze worse in mornings }\end{array}$ & Nil & $\begin{array}{l}20+\text { cigarettes daily } \\
\text { for } 30 \text { yrs }\end{array}$ & $\begin{array}{l}\text { Normal differential white } \\
\text { cell count. No eosinophils } \\
\text { in sputum }\end{array}$ \\
\hline$\underset{\mathbf{M}}{\mathbf{\text { D.B. }}}$ & $\begin{array}{l}\text { Daily cough worse in winter months and after colds } \\
20 \text { yrs. Sputum daily } 10 \mathrm{yrs} \text {, frequently purulent. } \\
\text { Progressive wheeze } 10 \mathrm{yrs} \text {. Cough much worse in } \\
\text { mornings }\end{array}$ & $\mathrm{Nil}$ & $\begin{array}{l}20+\text { cigarettes daily } \\
\text { for } 40 \text { yrs }\end{array}$ & $\begin{array}{l}\text { Normal differential white } \\
\text { cell count. No eosinophils } \\
\text { in sputum }\end{array}$ \\
\hline$\underset{53}{\text { A.J. }}$ & $\begin{array}{l}\text { Daily cough and sputum } 12 \text { yrs. Sputum purulent only } \\
\text { after colds. Daily wheeze } 8 \text { yrs, worse when sputum } \\
\text { purulent. Cough and wheeze much worse in } \\
\text { mornings }\end{array}$ & Nil & $\begin{array}{l}20+\text { cigarettes daily } \\
\text { for } 35 \text { yrs }\end{array}$ & $\begin{array}{l}\text { Normal differential white } \\
\text { cell count. No eosinophils } \\
\text { in sputum }\end{array}$ \\
\hline $\begin{array}{l}\text { E.C. } \\
\mathbf{4 8}\end{array}$ & $\begin{array}{l}\text { Daily cough } 20 \text { yrs. Daily sputum } 15 \text { yrs, infrequently } \\
\text { purulent. Daily mild wheeze } 10 \text { yrs, distressing } 6 \\
\text { mths. Cough and wheeze worse in mornings }\end{array}$ & $\begin{array}{l}\text { Healed pulmonary } \\
\text { tuberculosis }\end{array}$ & $\begin{array}{l}\text { 5-10 cigarettes daily } \\
\text { for } 30 \text { yrs }\end{array}$ & $\begin{array}{l}\text { Normal differential white } \\
\text { cell count. No eosinophils } \\
\text { in sputum }\end{array}$ \\
\hline $\begin{array}{l}\text { F.P. } \\
45\end{array}$ & $\begin{array}{l}\text { Winter 'bronchitis' } 20 \text { yrs. Daily cough } 3 \text { yrs. Sputum } \\
\text { daily } 3 \text { yrs, mainly mucoid. Progressive wheeze } \\
3 \text { yrs. Cough and wheeze worse in mornings }\end{array}$ & Nil & $\begin{array}{l}20+\text { cigarettes daily } \\
\text { for } 20 \mathrm{yrs}\end{array}$ & $\begin{array}{l}\text { Normal differential white } \\
\text { cell count. No eosinophils } \\
\text { in sputum }\end{array}$ \\
\hline$\underset{50}{\text { T.F. }}$ & $\begin{array}{l}\text { Winter cough most of life. Daily cough } 8 \text { yrs. Daily } \\
\text { sputum } 8 \text { yrs, mainly mucoid. Progressive daily } \\
\text { wheeze } 5 \text { yrs. Cough and wheeze worse in mornings }\end{array}$ & $\begin{array}{l}\text { Some form of eczema } \\
10 \text { yrs ago }\end{array}$ & $\begin{array}{l}10 \text { cigarettes daily } \\
\text { for } 32 \text { yrs }\end{array}$ & $\begin{array}{l}\text { Normal differential white } \\
\text { cell count. No eosinophils } \\
\text { in sputum }\end{array}$ \\
\hline$\underset{58}{\mathbf{F}}$ & $\begin{array}{l}\text { Winter cough } 15 \text { yrs. Daily cough } 2 \text { yrs. Daily sputum } \\
2 \text { yrs, frequently purulent. Daily wheeze } 2 \text { yrs. } \\
\text { Cough and wheeze much worse in mornings }\end{array}$ & Nil & Non-smoker & $\begin{array}{l}\text { Normal differential white } \\
\text { cell count. No eosinophils } \\
\text { in sputum }\end{array}$ \\
\hline$\underset{64}{\text { C.S. }}$ & $\begin{array}{l}\text { Winter cough } 20+\text { yrs. Daily cough } 2 \text { yrs. Sputum } \\
\text { rarely purulent. Daily. wheeze } 2 \text { yrs. Cough and } \\
\text { wheeze worse in mornings }\end{array}$ & Nil & $\begin{array}{l}15+\text { cigarettes daily } \\
\text { for } 40+y \text { ys }\end{array}$ & $\begin{array}{l}\text { Normal differential white } \\
\text { cell count. No eosinophils } \\
\text { in sputum }\end{array}$ \\
\hline
\end{tabular}


T A B L E I B

GROUP 1, CHRONIC BRONCHITIS : F.E.V.1.0(ml.) BEFORE AND 20 MIN. AFTER ADMINISTRATION OF THE ANTISPASMODIC DRUGS AND SALINE; AND F.E.V.1.0 IMMEDIATELY BEFORE AND SIX DAYS AFTER PREDNISOLONE THERAPY

\begin{tabular}{|c|c|c|c|c|c|c|c|c|}
\hline $\begin{array}{l}\text { Patients } \\
\text { Sex/Age }\end{array}$ & & $\begin{array}{l}\text { Adrenaline } \\
\text { s.c. }\end{array}$ & $\begin{array}{l}\text { Isoprenaline } \\
\text { Inhalation }\end{array}$ & $\begin{array}{c}\text { Aminophylline } \\
\text { i.v. }\end{array}$ & $\begin{array}{l}\text { Adrenaline } \\
\text { Inhalation }\end{array}$ & $\begin{array}{l}\text { Atropine } \\
\text { s.c. }\end{array}$ & $\begin{array}{c}\text { Saline } \\
\text { Inhalation }\end{array}$ & $\begin{array}{c}\text { Pred- } \\
\text { nisolone }\end{array}$ \\
\hline$\underset{\mathbf{F}}{\mathbf{F}}$ & $\begin{array}{l}\text { Before } \\
\text { After } \\
\% \text { improvement }\end{array}$ & $\begin{array}{l}350 \\
600 \\
74 \cdot 3\end{array}$ & $\begin{array}{l}240 \\
450 \\
87 \cdot 5\end{array}$ & $\begin{array}{l}370 \\
660 \\
78 \cdot 4\end{array}$ & $\begin{array}{l}400 \\
325 \\
-18 \cdot 8\end{array}$ & $\begin{array}{l}620 \\
700 \\
12 \cdot 9\end{array}$ & $\begin{array}{r}320 \\
320 \\
0\end{array}$ & $\begin{array}{l}350 \\
640 \\
82 \cdot 8\end{array}$ \\
\hline$\underset{\mathbf{5 8}}{\mathbf{F}}$ & $\begin{array}{l}\text { Before } \\
\text { After } \\
\% \text { improvement }\end{array}$ & $\begin{array}{l}1,400 \\
1,570 \\
12 \cdot 1\end{array}$ & $\begin{array}{l}1,200 \\
1,450 \\
20 \cdot 8\end{array}$ & $\begin{array}{l}1,420 \\
1,400 \\
-1 \cdot 4\end{array}$ & $\begin{array}{r}1,420 \\
1,470 \\
3 \cdot 5\end{array}$ & $\begin{array}{r}1,050 \\
1,500 \\
42 \cdot 8\end{array}$ & $\begin{array}{l}1,500 \\
1,420 \\
-5 \cdot 3\end{array}$ & $\begin{array}{l}1,420 \\
1,610 \\
11 \cdot 3\end{array}$ \\
\hline$\underset{63}{\text { J.D. }}$ & $\begin{array}{l}\text { Before } \\
\text { After } \\
\% \text { improvement }\end{array}$ & $\begin{array}{c}740 \\
1,000 \\
35 \cdot 1\end{array}$ & $\begin{array}{c}900 \\
1,100 \\
22 \cdot 2\end{array}$ & $\begin{array}{r}980 \\
1,050 \\
7 \cdot 1\end{array}$ & $\begin{array}{c}950 \\
1,050 \\
10 \cdot 5\end{array}$ & $\begin{array}{c}920 \\
1,100 \\
19 \cdot 6\end{array}$ & $\begin{array}{l}950 \\
900 \\
-5 \cdot 3\end{array}$ & $\begin{array}{c}980 \\
1,150 \\
17 \cdot 3\end{array}$ \\
\hline $\begin{array}{c}\text { W.R. } \\
\mathbf{F} \\
47\end{array}$ & $\begin{array}{l}\text { Before } \\
\text { After } \\
\% \text { improvement }\end{array}$ & $\begin{array}{r}700 \\
700 \\
0\end{array}$ & $\begin{array}{l}700 \\
800 \\
14 \cdot 3\end{array}$ & $\begin{array}{l}760 \\
850 \\
11 \cdot 8\end{array}$ & $\begin{array}{l}520 \\
690 \\
32 \cdot 7\end{array}$ & $\begin{array}{l}710 \\
890 \\
25 \cdot 4\end{array}$ & $\begin{array}{l}720 \\
660 \\
-8 \cdot 3\end{array}$ & $\begin{array}{c}710 \\
840 \\
18 \cdot 3\end{array}$ \\
\hline$\underset{55}{\mathbf{M}}$ & $\begin{array}{l}\text { Before } \\
\text { After } \\
\% \text { improvement }\end{array}$ & $\begin{array}{r}950 \\
1,340 \\
41 \cdot 0\end{array}$ & $\begin{array}{l}1,000 \\
1,330 \\
33 \cdot 0\end{array}$ & $\begin{array}{r}950 \\
1,250 \\
240\end{array}$ & $\begin{array}{c}950 \\
1,300 \\
36 \cdot 8\end{array}$ & $\begin{array}{l}1,000 \\
1,340 \\
34 \cdot 0\end{array}$ & $\begin{array}{r}1,000 \\
1,000 \\
0\end{array}$ & $\begin{array}{r}1,000 \\
1,000 \\
0\end{array}$ \\
\hline$\underset{\mathbf{M}}{\mathbf{M} . \mathbf{L}}$ & $\begin{array}{l}\text { Before } \\
\text { After } \\
\% \text { improvement }\end{array}$ & $\begin{array}{c}760 \\
980 \\
28.9\end{array}$ & $\begin{array}{l}500 \\
600 \\
20.0\end{array}$ & $\begin{array}{l}800 \\
920 \\
15.0\end{array}$ & $\begin{array}{l}700 \\
750 \\
7 \cdot 1\end{array}$ & $\begin{array}{l}1,200 \\
1,420 \\
18 \cdot 3\end{array}$ & $\begin{array}{c}1,000 \\
1,100 \\
10 \cdot 0\end{array}$ & $\begin{array}{c}1,000 \\
760 \\
-24 \cdot 0\end{array}$ \\
\hline$\underset{63}{\text { P.R. }}$ & $\begin{array}{l}\text { Before } \\
\text { After } \\
\% \text { improvement }\end{array}$ & $\begin{array}{c}600 \\
740 \\
23 \cdot 3\end{array}$ & $\begin{array}{c}800 \\
1,100 \\
37 \cdot 5\end{array}$ & $\begin{array}{c}840 \\
1,080 \\
28 \cdot 6\end{array}$ & $\begin{array}{c}850 \\
1,140 \\
34 \cdot 1\end{array}$ & $\begin{array}{c}800 \\
1,070 \\
33 \cdot 7\end{array}$ & $\begin{array}{l}650 \\
750 \\
15 \cdot 4\end{array}$ & $\begin{array}{l}800 \\
900 \\
12 \cdot 5\end{array}$ \\
\hline$\underset{65}{\text { R.G. }}$ & $\begin{array}{l}\text { Before } \\
\text { After } \\
\% \text { improvement }\end{array}$ & $\begin{array}{l}500 \\
660 \\
32 \cdot 0\end{array}$ & $\begin{array}{l}520 \\
700 \\
34 \cdot 6\end{array}$ & $\begin{array}{l}510 \\
540 \\
5.9\end{array}$ & $\begin{array}{l}500 \\
650 \\
30 \cdot 0\end{array}$ & $\begin{array}{l}500 \\
650 \\
30 \cdot 0\end{array}$ & $\begin{array}{l}500 \\
550 \\
10.0\end{array}$ & $\begin{array}{c}500 \\
540 \\
8.0\end{array}$ \\
\hline$\underset{\mathbf{M}}{\mathbf{J} . \mathrm{V}}$ & $\begin{array}{l}\text { Before } \\
\text { After } \\
\% \text { improvement }\end{array}$ & $\begin{array}{l}350 \\
380 \\
8 \cdot 6\end{array}$ & $\begin{array}{l}350 \\
450 \\
28.6\end{array}$ & $\begin{array}{l}400 \\
430 \\
7.5\end{array}$ & $\begin{array}{l}360 \\
540 \\
50 \cdot 0\end{array}$ & $\begin{array}{l}390 \\
620 \\
59 \cdot 0\end{array}$ & $\begin{array}{l}360 \\
320 \\
-11 \cdot 1\end{array}$ & $\begin{array}{c}360 \\
540 \\
50.0\end{array}$ \\
\hline $\begin{array}{l}\text { E.P. } \\
\mathbf{F} \\
36\end{array}$ & $\begin{array}{l}\text { Before } \\
\text { After } \\
\% \text { improvement }\end{array}$ & $\begin{array}{c}790 \\
1,490 \\
. \quad 88.6\end{array}$ & $\begin{array}{l}1,400 \\
1,500 \\
7 \cdot 1\end{array}$ & $\begin{array}{l}650 \\
1,460 \\
124 \cdot 6\end{array}$ & $\begin{array}{l}1,070 \\
1,360 \\
17 \cdot 0\end{array}$ & $\begin{array}{l}1,040 \\
1,660 \\
59.6\end{array}$ & $\begin{array}{l}640 \\
650 \\
1 \cdot 6\end{array}$ & $\begin{array}{l}1,400 \\
1,790 \\
27 \cdot 8\end{array}$ \\
\hline$\underset{\mathbf{M}}{\mathbf{J}} \mathbf{R}$ & $\begin{array}{l}\text { Before } \\
\text { After } \\
\% \text { improvement }\end{array}$ & $\begin{array}{l}1,360 \\
1,630 \\
19 \cdot 8\end{array}$ & $\begin{array}{l}1,230 \\
1,600 \\
30 \cdot 1\end{array}$ & $\begin{array}{l}1,010 \\
1,300 \\
30 \cdot 7\end{array}$ & $\begin{array}{r}1,010 \\
1,360 \\
34 \cdot 7\end{array}$ & $\begin{array}{l}1,450 \\
1,620 \\
11 \cdot 7\end{array}$ & $\begin{array}{r}1,060 \\
1,090 \\
2 \cdot 8\end{array}$ & $\begin{array}{l}1,360 \\
1,170 \\
-14 \cdot 0\end{array}$ \\
\hline$\underset{\mathbf{M 7}}{\text { D.B. }}$ & $\begin{array}{l}\text { Before } \\
\text { After } \\
\% \text { improvement }\end{array}$ & $\begin{array}{l}440 \\
450 \\
2 \cdot 3\end{array}$ & $\begin{array}{l}400 \\
460 \\
15 \cdot 0\end{array}$ & $\begin{array}{l}400 \\
480 \\
20.0\end{array}$ & $\begin{array}{r}420 \\
420 \\
0\end{array}$ & $\begin{array}{l}410 \\
490 \\
19 \cdot 5\end{array}$ & $\begin{array}{r}380 \\
380 \\
0\end{array}$ & $\begin{array}{l}400 \\
500 \\
25 \cdot 0\end{array}$ \\
\hline$\underset{53}{\text { A.J. }}$ & $\begin{array}{l}\text { Before } \\
\text { After } \\
\% \text { improvement }\end{array}$ & $\begin{array}{l}1,060 \\
1,270 \\
19 \cdot 8\end{array}$ & $\begin{array}{c}940 \\
1,220 \\
29 \cdot 8\end{array}$ & $\begin{array}{l}1,040 \\
1,260 \\
21 \cdot 1\end{array}$ & $\begin{array}{l}1,060 \\
1,230 \\
16 \cdot 0\end{array}$ & $\begin{array}{r}1,070 \\
1,400 \\
30 \cdot 8\end{array}$ & $\begin{array}{r}1,180 \\
1,250 \\
5 \cdot 9\end{array}$ & $\begin{array}{l}1,180 \\
1,130 \\
-4 \cdot 2\end{array}$ \\
\hline $\begin{array}{c}\text { E.C. } \\
48\end{array}$ & $\begin{array}{l}\text { Before } \\
\text { After } \\
\% \text { improvement }\end{array}$ & $\begin{array}{c}590 \\
860 \\
45 \cdot 8\end{array}$ & $\begin{array}{l}610 \\
920 \\
50 \cdot 8\end{array}$ & $\begin{array}{l}420 \\
490 \\
16 \cdot 7\end{array}$ & $\begin{array}{l}590 \\
940 \\
59 \cdot 3\end{array}$ & $\begin{array}{c}650 \\
1,040 \\
60 \cdot 0\end{array}$ & $\begin{array}{l}620 \\
610 \\
-1 \cdot 6\end{array}$ & $\begin{array}{l}640 \\
680 \\
6 \cdot 2\end{array}$ \\
\hline$\underset{45}{\text { F.P. }}$ & $\begin{array}{l}\text { Before } \\
\text { After } \\
\% \text { improvement }\end{array}$ & $\begin{array}{l}540 \\
740 \\
37 \cdot 0\end{array}$ & $\begin{array}{l}520 \\
760 \\
46 \cdot 1\end{array}$ & $\begin{array}{l}500 \\
760 \\
52 \cdot 0\end{array}$ & $\begin{array}{l}450 \\
640 \\
42 \cdot 2\end{array}$ & $\begin{array}{l}540 \\
800 \\
48 \cdot 1\end{array}$ & $\begin{array}{l}450 \\
480 \\
6 \cdot 7\end{array}$ & $\begin{array}{l}500 \\
460 \\
-8 \cdot 0\end{array}$ \\
\hline $\begin{array}{c}\text { T.F. } \\
\mathbf{M} \\
50\end{array}$ & $\begin{array}{l}\text { Before } \\
\text { After } \\
\% \text { improvement }\end{array}$ & $\begin{array}{l}1,230 \\
1,520 \\
23 \cdot 6\end{array}$ & $\begin{array}{l}1,160 \\
1,390 \\
19 \cdot 8\end{array}$ & $\begin{array}{r}1,110 \\
1,320 \\
18.9 \\
\end{array}$ & $\begin{array}{r}1,110 \\
1,260 \\
13 \cdot 5 \\
\end{array}$ & $\begin{array}{c}1,030 \\
1,590 \\
54 \cdot 4 \\
\end{array}$ & $\begin{array}{l}1,040 \\
1,030 \\
-1 \cdot 0\end{array}$ & $\begin{array}{l}1,280 \\
1,260 \\
-1 \cdot 6\end{array}$ \\
\hline $\begin{array}{c}\text { M.G. } \\
58\end{array}$ & $\begin{array}{l}\text { Before } \\
\text { After } \\
\% \text { improvement }\end{array}$ & $\begin{array}{l}1,000 \\
1,380 \\
38 \cdot 0\end{array}$ & $\begin{array}{c}1,120 \\
1,540 \\
37 \cdot 5\end{array}$ & $\begin{array}{l}1,220 \\
1,660 \\
36 \cdot 1\end{array}$ & $\begin{array}{l}1,070 \\
1,220 \\
14 \cdot 0\end{array}$ & $\begin{array}{l}1,330 \\
1,660 \\
24 \cdot 8\end{array}$ & $\begin{array}{r}1,090 \\
1,140 \\
4.6\end{array}$ & $\begin{array}{r}1,420 \\
1,360 \\
-4 \cdot 2\end{array}$ \\
\hline$\underset{64}{\text { C.S. }}$ & $\begin{array}{l}\text { Before } \\
\text { After } \\
\% \text { improvement }\end{array}$ & $\begin{array}{l}1,440 \\
1,730 \\
20 \cdot 1\end{array}$ & $\begin{array}{r}1,360 \\
1,760 \\
29 \cdot 4\end{array}$ & $\begin{array}{l}1,360 \\
1,560 \\
14 \cdot 7\end{array}$ & $\begin{array}{c}1,120 \\
1,690 \\
50.9\end{array}$ & $\begin{array}{r}1,440 \\
1,510 \\
4 \cdot 9\end{array}$ & $\begin{array}{c}1,000 \\
800 \\
-20.0\end{array}$ & $\begin{array}{r}1,360 \\
1,440 \\
5.9\end{array}$ \\
\hline
\end{tabular}


T A.B L E I I A

GROUP 2, CHRONIC ASTHMA

\begin{tabular}{|c|c|c|c|c|}
\hline $\begin{array}{l}\text { Patient } \\
\text { Sex/Age }\end{array}$ & $\begin{array}{l}\text { History of Cough } \\
\text { and Wheeze }\end{array}$ & $\begin{array}{l}\text { Other Points of } \\
\text { Significance }\end{array}$ & $\begin{array}{l}\text { Smoking } \\
\text { History }\end{array}$ & $\begin{array}{l}\text { Eosinophils in Blood } \\
\text { and Sputum }\end{array}$ \\
\hline$\underset{38}{\text { G.D. }}$ & $\begin{array}{l}\text { Recurrent attacks of wheeze as a child and young } \\
\text { adult. Daily wheeze } 5 \mathrm{mths} \text {. No cough or sputum }\end{array}$ & $\begin{array}{l}\text { Family history of } \\
\text { asthma }\end{array}$ & Non-smoker & $\begin{array}{l}\text { Normal differential white } \\
\text { cell count. No sputum } \stackrel{\overline{\mathscr{D}}}{\mathrm{Q}}\end{array}$ \\
\hline$\underset{41}{\text { A.V. }}$ & $\begin{array}{l}\text { Recurrent attacks of wheeze } 10 \text { yrs. Wheeze worse in } \\
\text { early summer. Free from symptoms in winter. } \\
\text { Daily wheeze } 6 \text { mths. Cough only at night. Sputum } \\
\text { mucoid and scanty }\end{array}$ & Nil & $\begin{array}{l}10 \text { cigarettes daily } \\
\text { until } 10 \text { yrs ago. } \\
\text { Stopped because } \\
\text { of wheeze }\end{array}$ & $\begin{array}{l}\text { Normal differential whitês } \\
\text { cell count. Eosinophils in } \\
\text { sputum }\end{array}$ \\
\hline$\underset{55}{\mathbf{M} . \mathbf{R}}$ & $\begin{array}{l}\text { Daily cough and wheeze } 7 \text { yrs. Wheezy as a child. } \\
\text { Scanty sputum always mucoid. Distressing noc- } \\
\text { turnal wheeze and cough }\end{array}$ & $\mathrm{Nil}$ & $\begin{array}{l}20+\text { cigarettes daily } \\
\text { until } 1 \text { mth before } \\
\text { study. Stopped be- } \\
\text { cause of symptoms }\end{array}$ & $\begin{array}{l}\text { Normal differential whitew } \\
\text { cell count. No eosinophile } \\
\text { in sputum }\end{array}$ \\
\hline$\underset{\mathbf{M}}{\mathbf{J} . \mathbf{H}}$ & $\begin{array}{l}\text { Daily wheeze and cough } 10 \text { yrs. Wheeze more dis- } \\
\text { tressing than cough. Symptoms fluctuant but no } \\
\text { complete freedom from cough or wheeze } 10 \text { yrs. } \\
\text { Scanty daily sputum frequently purulent. Mild } \\
\text { nocturnal exaggeration of symptoms }\end{array}$ & $\mathrm{Nil}$ & $\begin{array}{l}20+\text { cigarettes daily } \\
\text { for } 20 \text { yrs, } 10 \text { daily } \\
\text { for } 3 \text { yrs. Reduced } \\
\text { because of symp- } \\
\text { toms }\end{array}$ & $\begin{array}{l}\text { Normal differential whit } \\
\text { cell count. No eosinophils. } \\
\text { in sputum }\end{array}$ \\
\hline$\underset{44}{\text { M.K. }}$ & $\begin{array}{l}\text { Daily wheeze } 1 \mathrm{yr} \text {, gradual onset at menopause. Slight } \\
\text { cough at night. Scanty sputum rarely purulent. } \\
\text { Wheeze much worse at night }\end{array}$ & Eczema as a child & Non-smoker & $\begin{array}{l}\text { Normal differential white } \\
\text { cell count. No eosinophils } \\
\text { in sputum }\end{array}$ \\
\hline$\underset{35}{\mathbf{J} . \mathbf{B}}$ & $\begin{array}{l}\text { Wheeze } 19 \text { yrs with frequent exacerbations but no } \\
\text { complete freedom. Intermittent cough } 19 \text { yrs. Daily } \\
\text { cough and sputum } 2 \text { yrs. Sputum rarely purulent }\end{array}$ & Hay fever & $\begin{array}{l}5 \text { cigarettes daily for } \\
20 \text { yrs }\end{array}$ & $\begin{array}{l}\text { Normal differential whit } \\
\text { cell count. No eosinophil@్ } \\
\text { in sputum }\end{array}$ \\
\hline$\underset{68}{\text { G.E. }}$ & $\begin{array}{l}\text { Recurrent cough and wheeze } 4 \text { yrs. Freedom from } \\
\text { symptoms during spring months. Daily cough and } \\
\text { wheeze } 6 \text { mths. Sputum mucoid. Cough and } \\
\text { wheeze much worse at night }\end{array}$ & $\mathrm{Nil}$ & Non-smoker & $\begin{array}{l}\text { Normal differential whitę } \\
\text { cell count. No eosinophil } \\
\text { in sputum }\end{array}$ \\
\hline $\begin{array}{l}\text { R.A. } \\
\mathbf{6 2}\end{array}$ & $\begin{array}{l}\text { Recurrent wheeze } 20 \text { yrs. Wheeze most troublesome } \\
\text { in early summer. Cough associated with wheeze } \\
10 \text { yrs. Sputum mucoid and scanty. Freedom from } \\
\text { symptoms during late summer months }\end{array}$ & Nil & $\begin{array}{l}\text { Pipe smoker } 2 \text { oz. } \\
\text { tobacco per week }\end{array}$ & $\begin{array}{l}\text { Normal differential white } \\
\text { cell count. No eosinophil } \\
\text { in sputum }\end{array}$ \\
\hline $\begin{array}{l}\text { D.B. } \\
40\end{array}$ & $\begin{array}{l}\text { Recurrent wheeze as a child. Daily wheeze } 15 \text { yrs. } \\
\text { Daily cough } 10 \text { yrs. Sputum scanty but frequently } \\
\text { purulent. Nocturnal exaggeration of symptoms }\end{array}$ & $\begin{array}{l}\text { Family history of } \\
\text { asthma. Positive } \\
\text { skin test for Asper- } \\
\text { gillus fumigatus }\end{array}$ & Non-smoker & $\begin{array}{l}17 \% \text { eosinophils of } 10,50 \stackrel{8}{8} \\
\text { total white cell count } \\
\text { Eosinophils in sputum }\end{array}$ \\
\hline $\begin{array}{r}\text { H.C. } \\
\mathbf{3 2}\end{array}$ & $\begin{array}{l}\text { Recurrent wheeze } 20 \text { yrs. Daily wheeze } 7 \text { yrs. Inter- } \\
\text { mittent cough } 7 \text { yrs. Sputum scanty and mucoid. } \\
\text { Nocturnal exaggeration of symptoms }\end{array}$ & $\begin{array}{l}\text { Infantile eczema. } \\
\text { History of various } \\
\text { allergies }\end{array}$ & Non-smoker & $\begin{array}{l}13 \% \text { eosinophils of } 6,70 \stackrel{5}{5} \\
\text { total white cell count } \\
\text { Eosinophils in sputum }\end{array}$ \\
\hline $\begin{array}{l}\text { B.McS. } \\
\mathbf{3 4}\end{array}$ & $\begin{array}{l}\text { Chronic wheeze } 10 \text { yrs with numerous attacks of } \\
\text { distressing wheeze. Daily cough } 10 \text { yrs. Scanty } \\
\text { sputum always mucoid. Nocturnal exaggeration of } \\
\text { symptoms }\end{array}$ & Hay fever & $\begin{array}{l}10 \text { cigarettes daily } \\
\text { for } 16 \text { yrs. Stopped } \\
\text { because of exag- } \\
\text { geration of symp- } \\
\text { toms } 3 \text { yrs before } \\
\text { study }\end{array}$ & $\begin{array}{l}\text { Normal differential whit } \\
\text { cell count. No eosinophils } \\
\text { in sputum }\end{array}$ \\
\hline $\begin{array}{l}\text { H.B. } \\
44\end{array}$ & $\begin{array}{l}\text { Daily wheeze } 3 \text { yrs. Intermittent cough } 3 \text { yrs. Very } \\
\text { scanty mucoid sputum. Cough and wheeze much } \\
\text { worse at night }\end{array}$ & Nil & Non-smoker & $\begin{array}{l}9 \% \text { eosinophils of } 6,700 \text { tota } \Phi \\
\text { white cell count. No } \\
\text { eosinophils in sputum }\end{array}$ \\
\hline$\underset{44}{G . H .}$ & $\begin{array}{l}\text { Recurrent wheeze all his life. Daily wheeze } 5 \text { yrs. } \\
\text { Daily cough } 5 \text { yrs. Daily copious mucoid sputum } \\
5 \text { yrs. Nocturnal exaggeration of symptoms }\end{array}$ & $\mathrm{Nil}$ & $\begin{array}{l}20 \text { cigarettes daily } \\
\text { for } 20 \text { yrs. Stopped } \\
7 \text { yrs before study }\end{array}$ & $\begin{array}{l}\text { Normal differential white. } \\
\text { cell count. Eosinophils if } \\
\text { sputum }\end{array}$ \\
\hline $\begin{array}{l}\text { C.M. } \\
52\end{array}$ & $\begin{array}{l}\text { Recurrent wheeze } 10 \text { yrs. Constant daily wheeze } 8 \\
\text { mths. Daily cough } 6 \text { mths. Sputum daily, numerous } \\
\text { bronchial casts. Nocturnal exaggeration of } \\
\text { symptoms }\end{array}$ & $\begin{array}{l}\text { Allergy to house } \\
\text { dust. Eczema as a } \\
\text { child. Positive skin } \\
\text { test for Aspergillus } \\
\text { fumigatus }\end{array}$ & $\begin{array}{l}20 \text { cigarettes daily } \\
\text { for } 30 \text { yrs. Stopped } \\
3 \text { mths before study } \\
\text { because of symp- } \\
\text { toms }\end{array}$ & $\begin{array}{l}7 \% \text { eosinophils of } 7,8000 \\
\text { total white cell count. NRु } \\
\text { eosinophils in sputurd } \\
\text { (bronchial casts not seen } \\
\text { in hospital) }\end{array}$ \\
\hline$\underset{35}{\text { K.D. }}$ & $\begin{array}{l}\text { Recurrent wheeze } 10 \text { yrs. Chronic daily wheeze } 3 \text { yrs. } \\
\text { Intermittent cough } 3 \text { yrs. Sputum scanty and } \\
\text { mucoid }\end{array}$ & $\begin{array}{l}\text { 'Allergy' to aspirin. } \\
\text { Family history of } \\
\text { asthma }\end{array}$ & Non-smoker & $\begin{array}{l}\text { Normal differential whice } \\
\text { cell count. No eosinophif } \\
\text { in sputum }\end{array}$ \\
\hline$\underset{\mathbf{M}}{\text { D.McL: }}$ & $\begin{array}{l}\text { Chronic daily wheeze } 2 \text { yrs. Daily cough } 6 \text { mths. } \\
\text { Sputum mucoid and copious. Marked nocturnal } \\
\text { exaggeration of symptoms }\end{array}$ & $\begin{array}{l}\text { Family history of } \\
\text { asthma. Hay fever }\end{array}$ & $\begin{array}{l}\text { Non-smoker for } 10 \\
\text { yrs }\end{array}$ & $\begin{array}{l}10 \% \text { eosinophils of } 9,000 \\
\text { total white cell count. Not } \\
\text { eosinophils in sputum }\end{array}$ \\
\hline$\underset{\mathbf{J} . \mathbf{B}}{\mathbf{F}}$ & $\begin{array}{l}\text { Episodic wheeze all her life. Chronic wheeze } 10 \text { yrs. } \\
\text { Recurrent cough } 10 \text { yrs. Sputum scanty and mucoid. } \\
\text { Nocturnal exaggeration of symptoms }\end{array}$ & $\begin{array}{l}\text { Infantile eczema. } \\
\text { Hay fever. Family } \\
\text { history of asthma }\end{array}$ & $\begin{array}{l}5-10 \text { cigarettes daily } \\
\text { for } 10 \text { yrs. Stopped } \\
2 \text { yrs before study } \\
\text { because of symp- } \\
\text { toms }\end{array}$ & 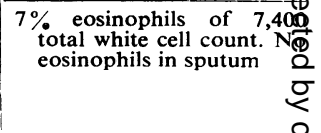 \\
\hline
\end{tabular}


T A B L E I I B

GROUP 2, CHRONIC ASTHMA: F.E.V $1 \cdot$ (ml.) BEFORE AND 20 MIN. AFTER ADMINISTRATION OF THE ANTISPASMODIC

\begin{tabular}{|c|c|c|c|c|c|c|c|c|}
\hline $\begin{array}{c}\text { Patient } \\
\text { Sex/Age }\end{array}$ & & $\begin{array}{l}\text { Adrenaline } \\
\text { s.c. }\end{array}$ & $\begin{array}{l}\text { Isoprenaline } \\
\text { Inhalation }\end{array}$ & $\begin{array}{c}\text { Aminophylline } \\
\text { i.v. }\end{array}$ & $\begin{array}{l}\text { Adrenaline } \\
\text { Inhalation }\end{array}$ & $\begin{array}{l}\text { Atropine } \\
\text { s.c. }\end{array}$ & $\begin{array}{c}\text { Saline } \\
\text { Inhalation }\end{array}$ & Prednisolone \\
\hline$\underset{\mathbf{M}}{\text { G.D. }}$ & $\begin{array}{l}\text { Before } \\
\text { After } \\
\% \text { improvement }\end{array}$ & $\begin{array}{l}2,800 \\
3,350 \\
19 \cdot 6\end{array}$ & $\begin{array}{l}2,420 \\
3,060 \\
26 \cdot 4\end{array}$ & $\begin{array}{l}2,200 \\
2,700 \\
22 \cdot 7\end{array}$ & $\begin{array}{l}3,200 \\
3,400 \\
6 \cdot 2\end{array}$ & $\begin{array}{r}2,250 \\
2,250 \\
0\end{array}$ & $\begin{array}{l}2,460 \\
2,420 \\
-1 \cdot 6\end{array}$ & $\begin{array}{l}2,250 \\
3,260 \\
44 \cdot 9\end{array}$ \\
\hline$\underset{41}{\text { A.V. }}$ & $\begin{array}{l}\text { Before } \\
\text { After } \\
\% \text { improvement }\end{array}$ & $\begin{array}{l}1,350 \\
1,580 \\
17 \cdot 0\end{array}$ & $\begin{array}{l}1,350 \\
1,740 \\
28.9\end{array}$ & $\begin{array}{l}1,140 \\
1,340 \\
17 \cdot 5\end{array}$ & $\begin{array}{l}1,460 \\
1,420 \\
-2 \cdot 0\end{array}$ & $\begin{array}{l}1,150 \\
1,070 \\
-8 \cdot 5\end{array}$ & $\begin{array}{l}1,560 \\
1,470 \\
-5.8\end{array}$ & $\begin{array}{l}1,140 \\
2,575 \\
125.9\end{array}$ \\
\hline $\begin{array}{c}\text { J.R. } \\
\mathbf{M 5}\end{array}$ & $\begin{array}{l}\text { Before } \\
\text { After } \\
\% \text { improvement }\end{array}$ & $\begin{array}{l}1,260 \\
1,850 \\
46 \cdot 8\end{array}$ & $\begin{array}{c}950 \\
1,510 \\
58.9\end{array}$ & $\begin{array}{l}1,100 \\
1,550 \\
40.9\end{array}$ & $\begin{array}{l}1,100 \\
1,500 \\
36 \cdot 4\end{array}$ & $\begin{array}{l}1,020 \\
1,240 \\
21 \cdot 6\end{array}$ & $\begin{array}{l}1,300 \\
1,310 \\
\theta \cdot 8\end{array}$ & $\begin{array}{l}1,300 \\
1,610 \\
23 \cdot 8\end{array}$ \\
\hline$\underset{\mathbf{3 4}}{\mathbf{J} . \mathrm{H}}$ & $\begin{array}{l}\text { Before } \\
\text { After } \\
\% \text { improvement }\end{array}$ & $\begin{array}{l}2,150 \\
2,830 \\
31 \cdot 6\end{array}$ & $\begin{array}{l}2,390 \\
3,190 \\
33 \cdot 5\end{array}$ & $\begin{array}{r}1,900 \\
2,670 \\
40.5\end{array}$ & $\begin{array}{l}2,400 \\
3,110 \\
29 \cdot 6\end{array}$ & $\begin{array}{l}2,000 \\
2,400 \\
20 \cdot 0\end{array}$ & $\begin{array}{r}2,100 \\
2,150 \\
2 \cdot 4\end{array}$ & $\begin{array}{l}2,400 \\
2,580 \\
7 \cdot 5\end{array}$ \\
\hline$\underset{\mathbf{F}}{\mathbf{M . K}}$ & $\begin{array}{l}\text { Before } \\
\text { After } \\
\% \text { improvement }\end{array}$ & $\begin{array}{l}1,000 \\
1,150 \\
15.0\end{array}$ & $\begin{array}{c}870 \\
1,100 \\
26 \cdot 4\end{array}$ & $\begin{array}{l}1,030 \\
1,310 \\
27 \cdot 2\end{array}$ & $\begin{array}{c}950 \\
1,090 \\
15.4\end{array}$ & $\begin{array}{c}860 \\
1,120 \\
30 \cdot 2\end{array}$ & $\begin{array}{l}850 \\
860 \\
1 \cdot 2\end{array}$ & $\begin{array}{c}870 \\
2,020 \\
132 \cdot 2\end{array}$ \\
\hline$\underset{35}{\mathbf{M} . \mathbf{B}}$ & $\begin{array}{l}\text { Before } \\
\text { After } \\
\% \text { improvement }\end{array}$ & $\begin{array}{l}1,330 \\
2,460 \\
85 \cdot 0\end{array}$ & $\begin{array}{l}1,140 \\
1,730 \\
51 \cdot 8\end{array}$ & $\begin{array}{c}880 \\
1,350 \\
53 \cdot 4\end{array}$ & $\begin{array}{l}1,040 \\
1,940 \\
86 \cdot 5\end{array}$ & $\begin{array}{r}1,180 \\
1,760 \\
49 \cdot 2\end{array}$ & $\begin{array}{l}1,360 \\
1,400 \\
2 \cdot 9\end{array}$ & $\begin{array}{r}2,150 \\
2,340 \\
8 \cdot 8\end{array}$ \\
\hline$\underset{\mathbf{6}}{\mathbf{M} . \mathrm{E}}$ & $\begin{array}{l}\text { Before } \\
\text { After } \\
\% \text { improvement }\end{array}$ & $\begin{array}{c}680 \\
1,480 \\
117 \cdot 6\end{array}$ & $\begin{array}{c}900 \\
1,260 \\
40 \cdot 0\end{array}$ & $\begin{array}{c}920 \\
1,180 \\
35 \cdot 6\end{array}$ & $\begin{array}{c}890 \\
1,150 \\
19 \cdot 8\end{array}$ & $\begin{array}{l}820 \\
920 \\
12 \cdot 2\end{array}$ & $\begin{array}{l}860 \\
870 \\
1 \cdot 2\end{array}$ & $\begin{array}{c}820 \\
1,620 \\
97.6\end{array}$ \\
\hline $\begin{array}{c}\text { R.A. } \\
\mathbf{\text { G2 }}\end{array}$ & $\begin{array}{l}\text { Before } \\
\text { After } \\
\% \text { improvement }\end{array}$ & $\begin{array}{l}590 \\
860 \\
45 \cdot 8\end{array}$ & $\begin{array}{l}670 \\
870 \\
29 \cdot 8\end{array}$ & $\begin{array}{l}570 \\
790 \\
38 \cdot 6\end{array}$ & $\begin{array}{l}610 \\
810 \\
32 \cdot 8\end{array}$ & $\begin{array}{l}610 \\
850 \\
39 \cdot 3\end{array}$ & $\begin{array}{r}610 \\
610 \\
0\end{array}$ & $\begin{array}{l}590 \\
940 \\
59 \cdot 3\end{array}$ \\
\hline $\begin{array}{c}\text { D.B. } \\
\mathbf{4 0}\end{array}$ & $\begin{array}{l}\text { Before } \\
\text { After } \\
\% \text { improvement }\end{array}$ & $\begin{array}{l}510 \\
650 \\
27 \cdot 4\end{array}$ & $\begin{array}{l}520 \\
550 \\
5.9\end{array}$ & $\begin{array}{l}440 \\
500 \\
18 \cdot 6\end{array}$ & $\begin{array}{l}470 \\
500 \\
6.4\end{array}$ & $\begin{array}{l}560 \\
490 \\
-12 \cdot 5\end{array}$ & $\begin{array}{l}550 \\
560 \\
1.8\end{array}$ & $\begin{array}{l}470 \\
760 \\
61 \cdot 7\end{array}$ \\
\hline$\underset{\mathbf{4 3}}{\mathbf{M} . T .}$ & $\begin{array}{l}\text { Before } \\
\text { After } \\
\% \text { improvement }\end{array}$ & $\begin{array}{l}420 \\
700 \\
66 \cdot 7\end{array}$ & $\begin{array}{l}450 \\
520 \\
15 \cdot 6\end{array}$ & $\begin{array}{l}420 \\
600 \\
42 \cdot 8\end{array}$ & $\begin{array}{l}440 \\
460 \\
4 \cdot 5\end{array}$ & $\begin{array}{l}410 \\
620 \\
51 \cdot 2\end{array}$ & $\begin{array}{l}400 \\
420 \\
5.0\end{array}$ & $\begin{array}{l}450 \\
730 \\
62 \cdot 2\end{array}$ \\
\hline$\underset{32}{\text { H.C. }}$ & $\begin{array}{l}\text { Before } \\
\text { After } \\
\% \text { improvement }\end{array}$ & $\begin{array}{c}980 \\
1,560 \\
59 \cdot 2\end{array}$ & $\begin{array}{c}900 \\
1,520 \\
68.9\end{array}$ & $\begin{array}{l}1,530 \\
1,810 \\
18 \cdot 3\end{array}$ & $\begin{array}{c}1,610 \\
1,620 \\
0.6\end{array}$ & $\begin{array}{l}1,430 \\
1,570 \\
9 \cdot 8\end{array}$ & $\begin{array}{r}1,430 \\
1,530 \\
7 \cdot 0\end{array}$ & $\begin{array}{l}1,800 \\
1,720 \\
-4 \cdot 4\end{array}$ \\
\hline$\underset{\text { M.McS. }}{\text { B4 }}$ & $\begin{array}{l}\text { Before } \\
\text { After } \\
\% \text { improvement }\end{array}$ & $\begin{array}{l}2,060 \\
2,950 \\
43 \cdot 2\end{array}$ & $\begin{array}{l}1,790 \\
2,500 \\
39 \cdot 7\end{array}$ & $\begin{array}{r}1,840 \\
2,060 \\
13 \cdot 6\end{array}$ & $\begin{array}{l}1,840 \\
2,610 \\
41 \cdot 8\end{array}$ & $\begin{array}{c}1,920 \\
1,780 \\
-7 \cdot 3\end{array}$ & $\begin{array}{c}1,600 \\
1,770 \\
10.6\end{array}$ & $\begin{array}{l}1,600 \\
1,800 \\
12.5\end{array}$ \\
\hline$\underset{44}{\text { H.B. }}$ & $\begin{array}{l}\text { Before } \\
\text { After } \\
\% \text { improvement }\end{array}$ & $\begin{array}{l}1,260 \\
1,610 \\
27 \cdot 8\end{array}$ & $\begin{array}{l}1,120 \\
1,280 \\
14 \cdot 3\end{array}$ & $\begin{array}{l}1,400 \\
1,600 \\
14 \cdot 3\end{array}$ & $\begin{array}{r}1,320 \\
1,410 \\
6 \cdot 8\end{array}$ & $\begin{array}{r}1,140 \\
1,190 \\
4 \cdot 4\end{array}$ & $\begin{array}{r}1,020 \\
1,210 \\
18.6\end{array}$ & $\begin{array}{l}1,400 \\
2,010 \\
43 \cdot 6\end{array}$ \\
\hline$\underset{\mathbf{F}}{\text { G.H. }}$ & $\begin{array}{l}\text { Before } \\
\text { After } \\
\% \text { improvement }\end{array}$ & $\begin{array}{l}1,480 \\
1,810 \\
26 \cdot 6\end{array}$ & $\begin{array}{l}1,430 \\
1,790 \\
25 \cdot 2\end{array}$ & $\begin{array}{l}1,500 \\
1,750 \\
16 \cdot 7\end{array}$ & $\begin{array}{l}1,470 \\
1,840 \\
25 \cdot 2\end{array}$ & $\begin{array}{l}1,400 \\
1,680 \\
20 \cdot 0\end{array}$ & $\begin{array}{l}1,460 \\
1,470 \\
0.7\end{array}$ & $\begin{array}{l}1,480 \\
1,210 \\
-15 \cdot 4\end{array}$ \\
\hline $\begin{array}{l}\text { C.M. } \\
\mathbf{M} \\
52\end{array}$ & $\begin{array}{l}\text { Before } \\
\text { After } \\
\% \text { improvement }\end{array}$ & $\begin{array}{l}1,580 \\
2,550 \\
61 \cdot 4\end{array}$ & $\begin{array}{l}2,150 \\
2,670 \\
24 \cdot 2\end{array}$ & $\begin{array}{l}2,780 \\
3,200 \\
15 \cdot 1\end{array}$ & $\begin{array}{l}1,840 \\
2,260 \\
22 \cdot 8\end{array}$ & $\begin{array}{r}1,960 \\
2,050 \\
4 \cdot 6\end{array}$ & $\begin{array}{r}1,260 \\
1,340 \\
6 \cdot 3\end{array}$ & $\begin{array}{l}1,260 \\
3,280 \\
160 \cdot 3\end{array}$ \\
\hline$\underset{35}{\text { K.D. }}$ & $\begin{array}{l}\text { Before } \\
\text { After } \\
\% \text { improvement }\end{array}$ & $\begin{array}{l}1,990 \\
3,420 \\
71 \cdot 8\end{array}$ & $\begin{array}{l}1,850 \\
3,100 \\
67.6\end{array}$ & $\begin{array}{l}1,280 \\
2,200 \\
71.9\end{array}$ & $\begin{array}{l}2,310 \\
3,360 \\
45 \cdot 4\end{array}$ & $\begin{array}{l}1,440 \\
1,820 \\
26 \cdot 4\end{array}$ & $\begin{array}{l}1,340 \\
1,280 \\
-4 \cdot 5\end{array}$ & $\begin{array}{l}1,850 \\
2,290 \\
23 \cdot 8\end{array}$ \\
\hline$\underset{\mathbf{M}}{\mathbf{M 0}}$ & $\begin{array}{l}\text { Before } \\
\text { After } \\
\% \text { improvement }\end{array}$ & $\begin{array}{l}2,410 \\
2,700 \\
12 \cdot 0\end{array}$ & $\begin{array}{l}2,510 \\
3,340 \\
33 \cdot 1\end{array}$ & $\begin{array}{l}2,400 \\
3,110 \\
29 \cdot 6\end{array}$ & $\begin{array}{l}2,750 \\
2,850 \\
\mathbf{3 6} \cdot 4\end{array}$ & $\begin{array}{r}2,580 \\
2,830 \\
9 \cdot 7\end{array}$ & $\begin{array}{l}2,440 \\
2,400 \\
-1 \cdot 6\end{array}$ & $\begin{array}{l}2,580 \\
3,400 \\
35 \cdot 6\end{array}$ \\
\hline$\underset{35}{\mathbf{F}}$ & $\begin{array}{l}\text { Before } \\
\text { After } \\
\% \text { improvement }\end{array}$ & $\begin{array}{l}1,740 \\
2,050 \\
17 \cdot 8\end{array}$ & $\begin{array}{l}1,500 \\
1,900 \\
26 \cdot 7\end{array}$ & $\begin{array}{l}1,100 \\
1,870 \\
70 \cdot 0\end{array}$ & $\begin{array}{l}1,550 \\
1,740 \\
12 \cdot 2\end{array}$ & $\begin{array}{l}1,020 \\
1,400 \\
37 \cdot 3\end{array}$ & $\begin{array}{r}1,100 \\
1,100 \\
0\end{array}$ & $\begin{array}{c}1,550 \\
1,730 \\
11 \cdot 6\end{array}$ \\
\hline
\end{tabular}




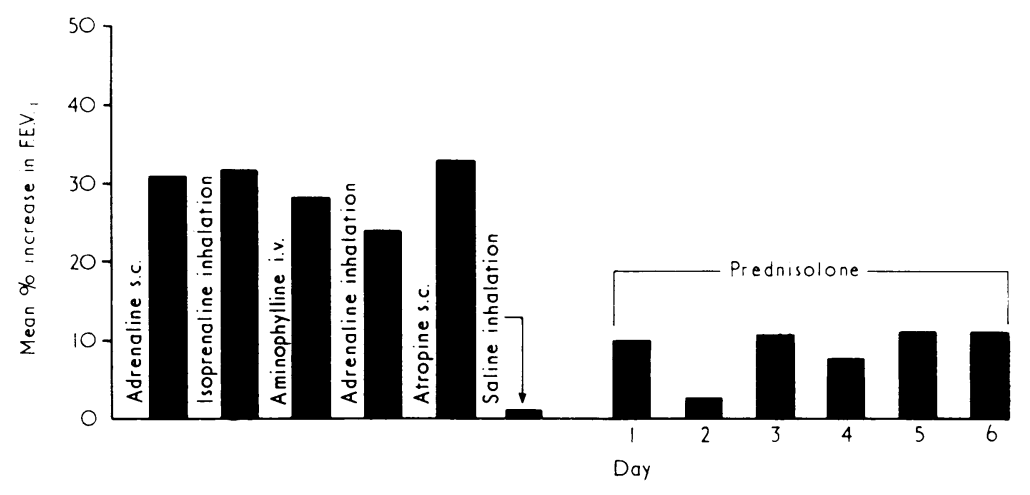

FIG. 1. Group 1, chronic bronchitis. Mean percentage increase in F.E.V. following the administration of the antispasmodic drugs, saline by inhalation. and prednisolone.

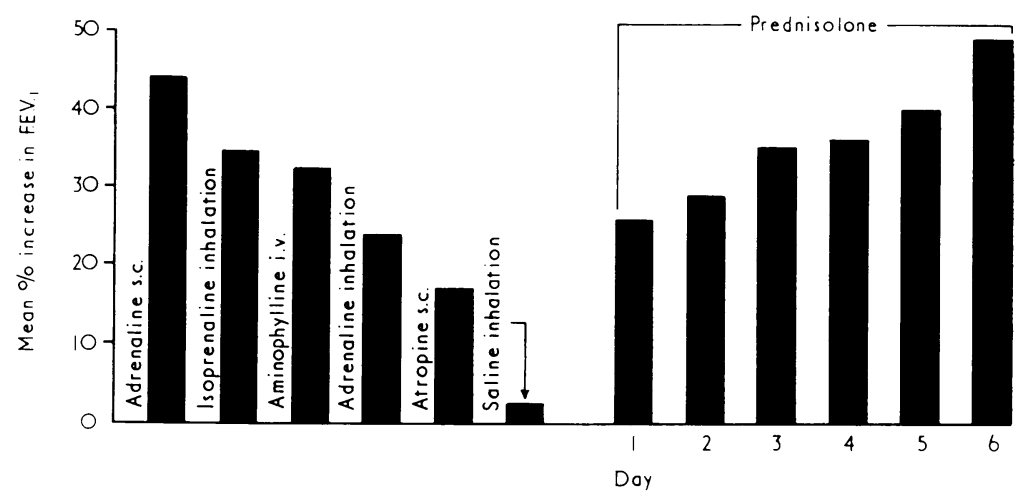

FlG. 2. Group 2, chronic asthma. Mean percentage increase in F.E.V. following the administration of the antispasmodic drugs, saline by inhalation, and prednisolone.

Figure 1 shows the mean changes in F.E.V ${ }_{\cdot 1 \cdot 11}$ for the 18 patients in the bronchitic group following the administration of the six test drugs and prednisolone. There is no significant difference between the responses to all five of the active substances used in the first part of the study. The mean improvement in F.E.V. ${ }_{\cdot \cdot \cdots}$ ranged from $24.1 \%$ after adrenaline inhalation to $32.5 \%$ following atropine sulphate. There was a mean improvement in F.E.V ${ }_{\cdot \cdot \cdot \|}$ after saline inhalation of $0 \cdot 2{ }^{\prime \prime \prime}$.

During the six-day period of prednisolone administration slight improvement occurred, which reached a mean value of $11.7 \%$ after six days. This improvement is not significant $(\mathrm{P}>$ $0.05<0 \cdot 1)$.

Figure 2 shows the mean changes in F.E.V.1. for the 18 patients in the asthmatic group follow- ing the administration of the six test drugs and prednisolone. There is considerable variation be- $\frac{O}{3}$ tween the responses to the six drugs used in the 0 first part of the study. The mean improvement in F.E.V.1.0 following administration of these drugs $\frac{7}{0}$ was $44 \%$ after subcutaneous adrenaline, $34.3 \%$ after isoprenaline inhalation, $32 \%$ after intra- $N$ venous aminophylline, $23.7 \%$ after adrenaline N inhalation, $17 \cdot 1 \%$ after subcutaneous atropine N sulphate, and $2.3 \%$ after saline inhalation. The $\omega$ difference between the mean response to subcutaneous adrenaline and isoprenaline inhalation is not significant $(P=0 \cdot 2)$, nor is the difference $\stackrel{D}{\mathscr{D}}$ between the mean response to subcutaneous $\overrightarrow{+}$ adrenaline and intravenous aminophylline $\left(P=\frac{0}{0}\right.$ $0 \cdot 1)$. There are significant differences between the $\overrightarrow{\mathbb{D}}$ mean F.E.V. ${ }_{1+\ldots}$ responses following subcutaneous $\frac{\rho}{\mathbb{Q}}$

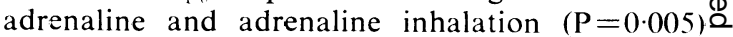
and subcutaneous atropine $(\mathrm{P}<0 \cdot 001)$. 
After prednisolone therapy had been started a significant improvement of $25.5 \%(\mathrm{P}<0.01>0.001)$ occurred after 24 hours and rose to $49.5 \%$ after six days' treatment $(\mathrm{P}<0.001)$.

All patients in both groups had a differential white cell count performed before the administration of prednisolone, and all patients, except for one in the chronic asthma group who had no sputum, had three specimens of sputum examined microscopically for eosinophils. One patient in the chronic bronchitic group had a significant increase of eosinophils in the peripheral blood, though none in this group had eosinophils in the three specimens of sputum examined. ${ }^{1}$ In contrast, four patients in the chronic asthma group had a significant peripheral blood eosinophilia, two had eosinophils in the sputum, and a further two had both eosinophils in the sputum and blood eosinophilia.

The eight patients in the chronic asthma group with sputum or blood eosinophilia or both did not respond significantly better to prednisolone than the 10 patients in whom no eosinophilia was demonstrated. The mean improvement in F.E.V.1.1 of the patients with eosinophilia after six days' prednisolone treatment was $53.4 \%$, compared with $47 \cdot 2 \%$ for the patients without eosinophilia ( $P>$ $0.8<0 \cdot 9$ ).

\section{DISCUSSION}

Strikingly different results were obtained in the two groups of patients studied. In the chronic bronchitics (group 1) the similarity of the responses to the short-acting bronchodilator drugs is impressive. There was a slightly greater improvement in the mean F.E.V. $\cdot_{\cdot 1 \cdot 0}$ after atropine sulphate, compared with the mean responses to the other drugs, but this was not statistically significant. In an independent study of patients with chronic bronchitis it was found that the improvement in F.E.V $\cdot_{\cdot \cdot \cdot 0}$ following the administration of atropinz sulphate subcutaneously continued for at least one hour (Fig. 3 and Table III). It is possible that, by recording the F.E.V $\cdot 1 \cdot 0$ administration the response to atropine sulphate in the present study has been underestimated. This is unlikely in the case of the other drugs used, as in a previous unpublished study of 30 wheezy patients maximum improvement in the mean F.E.V.$_{0 \cdot 75}$ was achieved by 20 minutes and

\footnotetext{
1I is possible that the incidence of eosinophils in the sputum varies in the course of the day, and this may be the explanation for the negative eosinophil sputum results in the patients who had a significant increase in the blood cosinophil count.
}

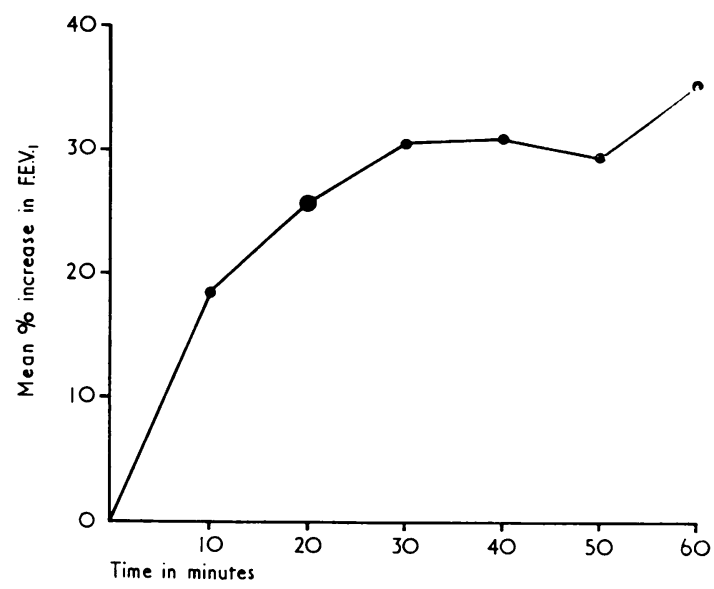

FIG. 3. Mean percentage increase in F.E. $V_{\cdot_{1 \cdot 0}}$ measured at intervals of 10 minutes for one hour after atropine sulphate, 0.6 mg. s.c., in 12 patients suffering from chronic bronchitis (patients not included in present study).

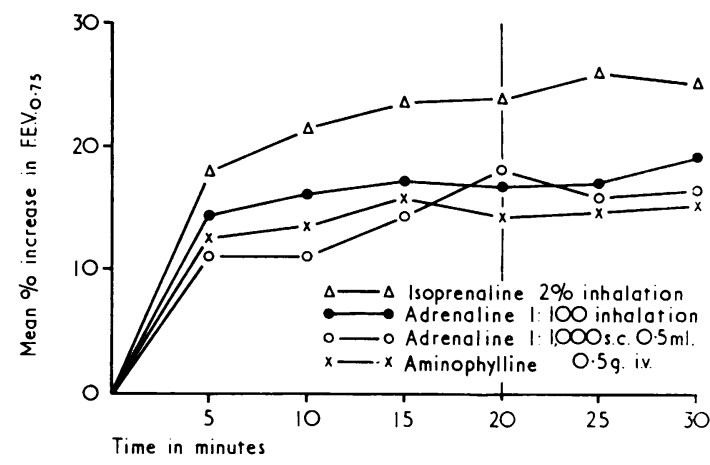

FIG. 4. Mean percentage increase in F.E.V..$_{0.75}$ measured at intervals of five minutes for 30 minutes following the administration of isoprenaline inhalation, adrenaline inhalation, subcutaneous adrenaline, and intravenous aminophylline to a group of 30 patients suffering from chronic bronchitis or chronic asthma (patients not included in present study).

no further improvement was observed at 30 minutes after administration of the drugs (Fig. 4). The improvement in the F.E.V $\cdot_{\cdot 1 \cdot 0}$ of bronchitic patients observed after the administration of atropine is not necessarily of therapeutic benefit, as some of the response may be due to drying of bronchial secretions, which in some patients can be harmful because of the danger of sputum retention. Only in a minority of patients with copious bronchial secretions may this effect of atropine be of benefit. 
T A B L E I I I

CHANGES IN F.E.V .1.0 (ml.) MEASURED AT 10-MIN. INTERVALS FOR 1 HOUR AFTER ADMINISTRATION OF ATROPINE SULPHATE, $0.6 \mathrm{mg}$. s.c., TO 12 CHRONIC BRONCHITIC PATIENTS NOT INCLUDED IN MAIN STUDY

\begin{tabular}{|c|c|c|c|c|c|c|c|c|}
\hline Case & & Initial & $10 \mathrm{Min}$. & $20 \mathrm{Min}$. & $30 \mathrm{Min}$. & $40 \mathrm{Min}$. & 50 Min. & $60 \mathrm{Min}$. \\
\hline 1 & $\%$ improvement & 770 & $\begin{array}{l}900 \\
16.9\end{array}$ & $\begin{array}{r}1,020 \\
32 \cdot 5\end{array}$ & $\begin{array}{r}1,030 \\
34\end{array}$ & $\begin{array}{l}1,000 \\
29 \cdot 7\end{array}$ & $\begin{array}{l}1,000 \\
29 \cdot 7\end{array}$ & $\begin{array}{l}1,020 \\
32 \cdot 5\end{array}$ \\
\hline 2 & $\%$ improvement & 750 & $\begin{array}{l}850 \\
13 \cdot 3\end{array}$ & $\begin{array}{r}920 \\
23\end{array}$ & $\begin{array}{l}890 \\
18 \cdot 7\end{array}$ & $\begin{array}{l}850 \\
13 \cdot 3\end{array}$ & $\begin{array}{r}780 \\
4\end{array}$ & $\begin{array}{r}750 \\
0\end{array}$ \\
\hline 3 & $\%$ improvement & 900 & $\begin{array}{r}1,010 \\
12 \cdot 2\end{array}$ & $\begin{array}{c}1,000 \\
11 \cdot 1\end{array}$ & $\begin{array}{l}950 \\
5 \cdot 5\end{array}$ & $\begin{array}{r}1,100 \\
22 \cdot 2\end{array}$ & $\begin{array}{r}1,090 \\
21\end{array}$ & $\begin{array}{r}1,130 \\
25 \cdot 5\end{array}$ \\
\hline 4 & $\%$ improvement & 700 & $\begin{array}{r}850 \\
22\end{array}$ & $\begin{array}{l}830 \\
18 \cdot 5\end{array}$ & $\begin{array}{l}880 \\
25 \cdot 6\end{array}$ & $\begin{array}{l}870 \\
24 \cdot 2\end{array}$ & $\begin{array}{l}900 \\
28 \cdot 5\end{array}$ & $\begin{array}{l}900 \\
28 \cdot 5\end{array}$ \\
\hline 5 & $\%$ improvement & 2,450 & $\begin{array}{r}2,840 \\
16\end{array}$ & $\begin{array}{l}2,900 \\
18 \cdot 4\end{array}$ & $\begin{array}{r}2,950 \\
20 \cdot 5\end{array}$ & $\begin{array}{r}2,990 \\
24\end{array}$ & $\begin{array}{l}3,100 \\
26 \cdot 5\end{array}$ & $\begin{array}{l}3,150 \\
28 \cdot 5\end{array}$ \\
\hline 6 & $\%$ improvement & 1,230 & $\begin{array}{r}1,590 \\
29\end{array}$ & $\begin{array}{r}1,900 \\
54 \cdot 5\end{array}$ & $\begin{array}{r}2,150 \\
75\end{array}$ & $\begin{array}{r}2,050 \\
66 \cdot 5\end{array}$ & $\begin{array}{r}2,140 \\
74\end{array}$ & $\begin{array}{r}2,300 \\
87\end{array}$ \\
\hline 7 & $\%$ improvement & 370 & $\begin{array}{r}490 \\
32\end{array}$ & $\begin{array}{l}460 \\
24 \cdot 4\end{array}$ & $\begin{array}{r}500 \\
35\end{array}$ & $\begin{array}{r}510 \\
38\end{array}$ & $\begin{array}{l}520 \\
40 \cdot 5\end{array}$ & $\begin{array}{r}600 \\
62\end{array}$ \\
\hline 8 & $\%$ improvement & 420 & $\begin{array}{r}520 \\
24\end{array}$ & $\begin{array}{l}620 \\
47 \cdot 5\end{array}$ & $\begin{array}{l}600 \\
42 \cdot 7\end{array}$ & $\begin{array}{l}600 \\
42 \cdot 7\end{array}$ & $\begin{array}{r}640 \\
52\end{array}$ & $\begin{array}{l}600 \\
42 \cdot 7\end{array}$ \\
\hline 9 & $\%$ improvement & 650 & $\begin{array}{l}700 \\
7 \cdot 7\end{array}$ & $\begin{array}{l}750 \\
15 \cdot 4\end{array}$ & $\begin{array}{r}800 \\
23\end{array}$ & $\begin{array}{r}840 \\
29\end{array}$ & $\begin{array}{r}880 \\
35\end{array}$ & $\begin{array}{l}830 \\
27 \cdot 5\end{array}$ \\
\hline 10 & $\%$ improvement & 750 & $\begin{array}{l}850 \\
13 \cdot 4\end{array}$ & $\begin{array}{r}870 \\
16\end{array}$ & $\begin{array}{l}950 \\
26 \cdot 5\end{array}$ & $\begin{array}{r}930 \\
24\end{array}$ & $\begin{array}{r}870 \\
16\end{array}$ & $\begin{array}{l}920 \\
22 \cdot 5\end{array}$ \\
\hline 11 & $\%$ improvement & 800 & $\begin{array}{l}900 \\
12 \cdot 6\end{array}$ & $\begin{array}{l}970 \\
21 \cdot 4\end{array}$ & $\begin{array}{r}1,050 \\
31 \cdot 3\end{array}$ & $\begin{array}{r}1,030 \\
28 \cdot 7\end{array}$ & $\begin{array}{l}1,050 \\
31 \cdot 3\end{array}$ & $\begin{array}{l}1,100 \\
37 \cdot 5\end{array}$ \\
\hline 12 & $\%$ improvement & 930 & $\begin{array}{r}1,070 \\
15\end{array}$ & $\begin{array}{l}1,160 \\
24 \cdot 7\end{array}$ & $\begin{array}{r}1,150 \\
23 \cdot 5\end{array}$ & $\begin{array}{r}1,250 \\
34 \cdot 5\end{array}$ & $\begin{array}{r}1,200 \\
29\end{array}$ & $\begin{array}{r}1,220 \\
31\end{array}$ \\
\hline & $\begin{array}{l}\text { Mean } \% \\
\text { improvement }\end{array}$ & & $17 \cdot 9$ & $25 \cdot 6$ & $30 \cdot 4$ & $31 \cdot 4$ & $29 \cdot 8$ & $35 \cdot 4$ \\
\hline
\end{tabular}

The responses to the short-acting bronchodilator drugs in the group of patients with chronic asthma (group 2) differed markedly from the group 1 results. The greatest improvement in the mean F.E.V.1.0 occurred after subcutaneous adrenaline, but this response was not significantly greater than the mean F.E.V..$_{1 \cdot 0}$ improvement following isoprenaline inhalation or intravenous aminophylline. The significant difference between the mean F.E.V.1.0 responses to subcutaneous adrenaline and adrenaline inhalation is not in accord with the work of Kennedy (1961), who reports that both methods of administration of adrenaline cause similar responses in asthmatic patients. The inhalation dose of adrenaline used in the present study was large-approximately 3 mg. delivered from the Wright nebulizer to the face mask - and hence it is unlikely that a small dose of adrenaline was responsible for the relatively poor mean response to adrenaline inhalation. Following the inhalation of adrenaline the response is maintained for longer than 20 minutes, and hence the time of F.E.V.1.0 recording can be excluded as a cause of this difference between the mean responses following inhalation and injection of adrenaline.
The patients selected were not severely disabled by their wheeze and breathlessness at the time of the study. None of the chronic asthma patients selected was ill enough to require immediate treatment with prednisolone. The mean F.E.V $\cdot_{1 \cdot 0}$ of the asthma patients before the first treatment was $1,340 \mathrm{ml}$., and only slight daily fluctuation of the mean basal F.E.V $\cdot_{1 \cdot 0}$ occurred during the six days of the first part of the study (range 1,300 to 1,400 $\mathrm{ml}$.). As the patients were not in a severe stage of the disease and there was only slight daily fluctuation in the mean pre-treatment F.E.V..$_{\cdot 1 \cdot 0}$ values, it can be assumed that adrenaline inhalation was not given at a time when the patient's asthma was so severe that a poor response could be expected (Hume and Gandevia, 1957 ; Kennedy, 1961).

Atropine sulphate produced only slight improvement in the mean F.E.V $\cdot_{1 \cdot 0}$ in the asthmatic group, and this response is significantly less than the responses to the other active drugs used: except for adrenaline by inhalation. This finding is in agreement with previous reports which state that the atropine compounds alone, by aerosol or injection, are of little or no value in the treatment of asthma (Pearson, 1958 ; Herxheimer, 1959). 
When the responses to the active drugs in the chronic bronchitic and the asthmatic groups are compared, the outstanding difference is in the response to atropine-a good response in the bronchitic group and a poor response in the asthmatic group. A good response to subcutaneous adrenaline was observed in both groups. When the responses to subcutaneous adrenaline and atropine in both groups are considered together with the insignificant improvement after prednisolone in group 1 and the good response to prednisolone in group 2, it is tempting to postulate that a significantly better response to subcutaneous adrenaline than to subcutaneous atropine is more in favour of an expected satisfactory prednisolone response than are equally good responses to subcutaneous adrenaline and subcutaneous atropine. The numbers of patients studied were small, however, and some variations of the subcutaneous adrenaline and atropine responses occurred within the groups. This is worthy of further study, since a poor response to aerosol atropine compared with aerosol isoprenaline has been observed in patients whose airways obstruction responds to corticosteroids, and similar responses to aerosol atropine and isoprenaline in patients whose bronchospasm was unaffected by corticosteroid therapy have also been reported (Altounyan, 1964 ; Gandevia, 1965). Aerosol atropine methonitrate produces a more rapid response in patients regarded as having chronic bronchitis than in patients with uncomplicated asthma (Gandevia, 1965). It is possible that atropine compounds have different actions in different forms of airway obstruction, and further study is necessary.

Prednisolone produced insignificant improvement in the mean F.E.V.1.0 in the bronchitic patients. This finding is in agreement with the results of other studies of corticosteroid drugs in chronic bronchitis and emphysema (Freedman, 1963 ; Cullen and Reidt, 1960 ; Lorriman, 1959). Some of the patients did, however, experience subjective improvement out of all proportion to the ventilatory improvement recorded.

The mean F.E.V.1.0 response to prednisolone of the chronic asthmatic patients, which reached a value of $49.5 \%$ after six days' treatment, was not unexpected, as patients suffering from chronic asthma can be expected to respond to corticosteroid drugs (Thursby-Pelham and Kennedy, 1958 ; Somner et al., 1960 ; Phear et al., 1960).
The different responses to prednisolone in the two groups are evidence in favour of a correct initial clinical diagnosis of chronic bronchitis and chronic asthma.

Eight of the 18 patients with chronic asthma studied were found to have sputum eosinophilia and/or significant peripheral blood eosinophilia. It has been reported that asthmatic patients with sputum eosinophilia respond well to corticosteroid therapy (Brown, 1958). In this study the patients with eosinophilia did not respond significantly better to prednisolone than did those in whom no eosinophilia was demonstrated.

This work was supported by a Medical Research Council grant. It gives me great pleasure to thank Professor J. W. Crofton and Dr. A. C. Douglas for their advice and encouragement; Mr. S. A. Sklaroff and Miss S. Merchant for their invaluable help in the statistical analysis of the results; and Mr. T. C. Dodds, of the Medical Photography Unit, for the preparation of the figures. I should also like to thank Miss J. Holywell for secretarial assistance.

\section{REFERENCES}

Altounyan, R. E. C. (1964). Variation of drug action on airway obstruction in man. Thorax, 19, 406.

Brown, H. Morrow (1958). Treatment of chronic asthma with prednisolone: significance of eosinophils in the sputum. Lancet, 2 , 1245.

Cullen, J. H., and Reidt, W. U. (1960). A study of the respiratory effect of prednisolone in diffuse airway obstruction. Amer. Rev. resp. Dis., 82, 508.

Finnegan, J. K. (1950). Stramonium cigarettes and powders. Bull. nat. Formulary Comm., Vol. 18, 131.

Freedman, B. J. (1963). Bronchodilators and corticosteroids in chronic bronchitis and emphysema. Brit. med. J., 2, 1509.

Gandevia, B. H. (1965). The reversibility of airways obstruction in asthma. In Trans. World Asthma Conference, 1965, Eastbourne. Chest and Heart Association, London.

Herxheimer, H. (1959). Atropine cigarettes in asthma and emphysema. Brit. med. J., 2, 167.

Hume, K. M., and Gandevia, B. (1957). Forced expiratory volume before and after isoprenaline. Thorax, 12, 276.

- and Rhys Jones, E. (1961). The response to bronchodilators in intrinsic asthma. Quart. J. Med., 30, 189.

Kennedy, M. C. S. (1961). The assessment of bronchodilators. Proc. Tuberc. Res. Coun., No. 48, p. 81.

Lewinsohn, H. C., Capel, L. H., and Smart, J. (1960). Changes in forced expiratory volumes throughout the day. Brit. med. J., $1,462$.

Lorriman, G. (1959). The effects of bronchodilators on pulmonary ventilation and diffusion in asthma and emphysema. Thorax, 14, 146.

McKerrow, C. B., McDermott, M., and Gilson, J. C. (1960). A spirometer for measuring the forced expiratory volume with a simple calibrating device. Lancet, 1, 149.

Pearson, R. S. Bruce (1958). Asthma. Brit. med. J., 2, 905.

Phear, D., Ball, K., and Page, F. (1960). Prolonged treatment with steroids in severe chronic asthma. Lancet, 1, 139.

Somner, A. R., Rogan, M. C., and Grant, I. W. B. (1960). Prolonged corticosteroid therapy in chronic asthma. Brit. med. J., 1, 1092.

Thursby-Pelham, D. C., and Kennedy, M. C. S. (1958). Prednisolone compared with cortisone in treatment of children with chronic asthma. Ibid., 1, 243. 